\title{
Stress, Stressors and Undergraduate Students: A Mini-Review
}

\author{
Ruchi Kothari ${ }^{1} *$, Snigdha Sharma², Pradeep Bokariya ${ }^{3}$
}

\begin{abstract}
Stressors are defined as personal and environmental experiences which result in stress. Universities are considered as excellent centers for education, yet some students fail to benefit due to various reasons. ${ }^{[1]}$ Education is one of the basic needs and in turn a right of all human beings. Student life has many benefits, but it also imposes inexorable stress. The environment of medical education and practice has long been considered a stressful one. ${ }^{[2]}$ Stress in medical students is not uncommon and is process orientated. After entering a medical college, a student for the first-time experience so closely so many peoples 'joy as during child birth and sorrow as during death of a patient in a place which may cause some emotional disturbance to the student also for the beginning phases of student life. ${ }^{[3]}$ In this review, we have tried to gauge some of the reasons behind it and caste a glance on the various studies conducted so far. Though we have tried majorly to include researches pertaining to Stress and stressor amongst medical students across the globe, we have also evaluated the role of stress in other faculties too. A few introductory remarks on role of parents in coping with this burning issue along with concept of Burnout have also been incorporated.
\end{abstract}

Key words: Academic stress, Medical education, Role of parents, Stressors, Undergraduate medical education.

\section{INTRODUCTION}

\section{Ruchi Kothari ${ }^{1, *}$, Snigdha Sharma², Pradeep Bokariya ${ }^{3}$}

'Department of Physiology, Mahatma Gandhi Institute of Medical Sciences, SEVAGRAM, Wardha, Maharashtra442102, INDIA.

${ }^{2}$ Second MBBS Student, Mahatma Gandhi Institute of Medical Sciences, SEVAGRAM, Wardha, Maharashtra442102, INDIA.

${ }^{3}$ Department of Anatomy, Mahatma Gandhi Institute of Medical Sciences, SEVAGRAM, Wardha, Maharashtra442102, INDIA.

\section{Correspondence}

\section{Dr. Ruchi Kothari}

Associate Professor, Department of Physiology, Mahatma Gandhi Institute of Medical Sciences, SEVAGRAM, Wardha, Maharashtra- 442102, INDIA.

Phone: +91-9730216884

Email: ruchi@mgims.ac.in

\section{History}

- Received: 17-07-2018

- Revised: 04-09-2018;

- Accepted: 20-09-2018.

\section{DOI : 10.5530/ijcep.2018.5.3.2}

\section{Copyright}

(C) 2018 Phcog.Net. This is an openaccess article distributed under the terms of the Creative Commons Attribution 4.0 International license.
Universities are considered as excellent centers for education, yet some students fail to benefit due to various reasons. ${ }^{[1]}$ Education is one of the basic needs and in turn a right of all human beings. Student life has many benefits, but it also imposes inexorable stress. The environment of medical education and practice has long been considered a stressful one. ${ }^{[2]}$ Stress in medical students is not uncommon and is process orientated. After entering a medical college, a student for the first-time experience so closely so many peoples 'joy as during child birth and sorrow as during death of a patient in a place. These may cause some emotional disturbance to the student also for the beginning phases of student life. ${ }^{[3]}$ Several educationists and sociologists pointed out that various student problems severely affect their learning process. A high level of stress is known to have a negative effect on cognitive functioning and learning of students in a medical school which affects their studies and mental health. ${ }^{[4]}$ Studies show that one exposure to acute stress affects information processing in the cerebellum which is the area of the brain responsible for motor control and movement coordination and is involved in learning and memory formation. The results show that emotional stress affects motor coordination and other cognitive functions. ${ }^{[5]}$

\section{SEARCH STRATEGY AND SELECTION CRITERIA}

In this review, we aimed to gauge some of the reasons behind stress and to caste a glance on the various studies conducted so far. We tried to include researches pertaining to Stress and stressor amongst medical students across the globe. We began with background reading about the topic, tracing the specific resources, we extensively searched the literature and analyzed the shortcomings and strengths of various workers. Methodologies and findings of the different studies were tabulated in chronological manner and an attempt was made to derive at an inference incorporating the previous, recent and finally our own perspective regarding the relationship of stress and students. Multiple database searches using MedLine, Google scholar, EMBASE and PubMed were conducted to identify all the previous as well as the recent studies and publications pertinent to this issue. All identified documents were examined and those that involved study of stress in medical students were retrieved for inclusion in the review. The relevant reports were compiled and important conclusions from the studies were laid down in proper chronology. The methodologies and findings of various authors were tabulated for a quick glance and to make easy comparisons between them. Reference lists of retrieved documents were hand searched to identify the additional publications followed by a critical analysis of the relationship among the different works.

\section{Concept of Stress}

Hans Selye discovered Stress in 1935 as a syndrome occurring in laboratory rats. In the modern world,

Cite this article: Kothari R, Sharma S, Bokariya P. Stress, Stressors and Undergraduate Students: A Mini-Review. Int J Clin Exp Physiol. 2018;5(3):114-9. 
Stress has become a universal explanation for human behavior. Selye described stress as a nonspecific response of the body to change. ${ }^{[6]}$ It is described as wear and tear our bodies experience in order to adjust to our changing environment. On one hand, stress compels us to take action while on the other hand, it results in feelings of rejection, anger and depression, leading to health problems such as headaches, upset stomach rashes, insomnia, ulcers, high blood pressure, heart disease and stroke. Stress affects our personal as well as professional lives and how can we expect proficient doctors when they are themselves a robot operated by stress?.

Everyone has to cope with different kinds of pressure laid down by the society and family. On the verge of coping with the factors, an individual himself unconsciously frames a trap and is caught in the vicious cycle. Several studies have been performed to evaluate the level of stress and various stress factors affecting a medical student having an impact on his/her personal as well as professional life.

\section{Stressors and their relation to stress}

Personal and environmental events that lead to stress are referred to as stressors. ${ }^{[7]}$ Depending upon their cultural backgrounds, personal traits, experience and coping skills, medical students may perceive the same stressors differently. Many studies have described the stressors of medical training and the associated negative consequences on the mental and physical health of medical students.

The stressors don't cause anxiety or tension by themselves. Instead, stress results from the interaction between stressors and the individual's perception and reaction to those stressors In short, stress includes the emotional disturbances or changes caused by stressors. As per Linn and Zeppa ${ }^{[8]}$ some stress in medical school training is needed for learning but how true is it? Is stress necessary for students to perform better or is this just the way they are programmed over the years?

As an attempt to have a deeper insight on the different stressors influencing a medical student's life, a cross-sectional anonymous questionnaire-based survey was conducted including all students from first to fourth year of a medical college in India by Singh A et al. using Beck depression inventory to assess the level of depression with a score of 12 or higher considered depressive. A total of 336 students participated giving a response rate of $88 \%$ out of which, $49.1 \%$ students were reported to have depressive symptoms. It was seen to be significantly higher in 1st year (59.3\%) and $2^{\text {nd }}$ year (65.6\%), as compared to 3 rd (34.4\%) and 4 th year $(37.2 \%)$ students $[p<0.05)$. Substance abuse $(p<0.0001)$, first and second year of study, female sex and language of instruction other than English at $10+2$ level were found to be associated factors for the development of depressive symptoms $[p<0.05]$.Symptoms suggestive of depression were found in $49.1 \%$ of the medical students. ${ }^{[9]}$

A cross-sectional study by Sarkar D et al. was conducted in the department of Physiology at Pt. Jawahar Lal Memorial Medical College Raipur. Medical Students Stressor Questionnaire 24 (MSSQ) was used to identify sources of stress. After Analysis, it was stated that, the Academic Related Stress (3.10), Intrapersonal and interpersonal related stress levels (2.96), Teaching and learning related stress (2.45) was high among the first-year undergraduate students. So, the Academic, Intrapersonal and interpersonal, Teaching and learning related stress (2.45) were stated to be the major sources of stress among the students. Social related stress (2.15), was the next high source followed by motivation related (1.92) and group activities related stress (1.71) in that order, in all of whom the stress levels was mild. ${ }^{[10]}$

In the same time span, studies have been performed in other countries to assess the level of stress and different factors responsible for inducing stress. Their comparative account has been elaborated in Table 1.
A comparison has been done in this review as an attempt to understand better the common stress factors among students across the globe.

\section{PREVIOUS RESEARCHES ON STRESS IN MEDICAL STUDENTS}

In a qualitative research conducted by Supe AN et al. at Seth G S medical college, Mumbai, (India) medical students at various stages of MBBS course majority of medical students $175 / 238$ i.e., (73\%) perceived stress which implied that stress in medical students is common and is process oriented. It was reported to be high in second and third year. ${ }^{[1]}$

Academic factors were the grander perceived cause of stress in medical students of the college. Emotional factors were found to be significantly more in First MBBS. It was believed to be dependent on person's ways of coping and social support.

Another study conducted by Dahlin $\mathrm{M}$ et al. assessed the exposure to different stressors and the prevalence of depression among medical students (including males and females). A total of 342 students from 1,3 and $6^{\text {th }}$ year were included in the study. The response rate was $90.4 \%$. First year students showed high ratings to the workload and lack of feedback stressors. Third year students gave high ratings to factors like 'Worries about future endurance/competence' and 'Pedagogical shortcomings'. In $6^{\text {th }}$ year, both these factors were rated highly, but Year 6 students also showed higher ratings than the 2 other groups to 'Non-supportive climate'. It was also observed that medical students had higher depression rates than the general population and women students were found to have a higher rate than men. ${ }^{[12]}$

A descriptive cross sectional study was performed on all the registered and studying undergraduate medical students of S. Nijalingappa Medical College, Bagalkot in by Mannapur B which showed a higher level of stress in repeaters. The study was performed using a specially designed Self Reporting Questionnaire (SRQ) schedule which contained a set of questions which were related to 1) Socio-demographic profiles 2) Psychological stress and 3) Unhealthy habits. The dietary pattern of the study subjects was mainly the mixed type (62.95\%). $71.71 \%$ of the students were performing physical exercises. $9.16 \%$ and $11.55 \%$ of the students had a habit of smoking and alcohol intake, respectively. $42.63 \%$ of the study subjects were found to have experienced less/moderate stress and $47.01 \%$ of them had experienced severe stress. A total of $89.64 \%$ of the study subjects had experienced stress.68.57\% of the repeaters had severe stress as compared to $43.52 \%$ stress cases among regular students. The stress was found to be more among repeaters as compared to the non-repeaters. ${ }^{[13]}$

Another study carried out during academic examination in final year medical students at Sri Aurobindo Institute of Medical Sciences, Indore by Sharma B et al. Assessed stress and its effect on vital parameters. The final MBBS students of academic year 2010-11 were selected for the study using Zung's scale for assessment of Stress. Out of 68 students 39 (57.4\%) were boys and $29(42.6 \%)$ were girls. Major proportion of population $38.2 \%$ was found to have mild stress, $32.4 \%$ were normal while $19.1 \%$ suffered from marked major stress and $10.3 \%$ were in extreme major stress category in total studied subjects. The major proportion of boys $43.6 \%$ and girls $31.0 \%$ had mild stress, $33.3 \%$ boys and $31.0 \%$ girls were normal, $15.4 \%$ and $24.1 \%$ boys and girls suffered from marked major stress and $7.7 \%$ and $13.8 \%$ boys and girls were in extreme major stress category respectively. A significant difference between before and at the time of examination observations in vital parameters (Pulse Rate, Systolic Blood Pressure and Diastolic Blood Pressure) due to examination stress was also observed also, a positive and very high degree of correlation $(p<0.01)$ was seen between weight, height and BMI both at the time of examination and before examination 

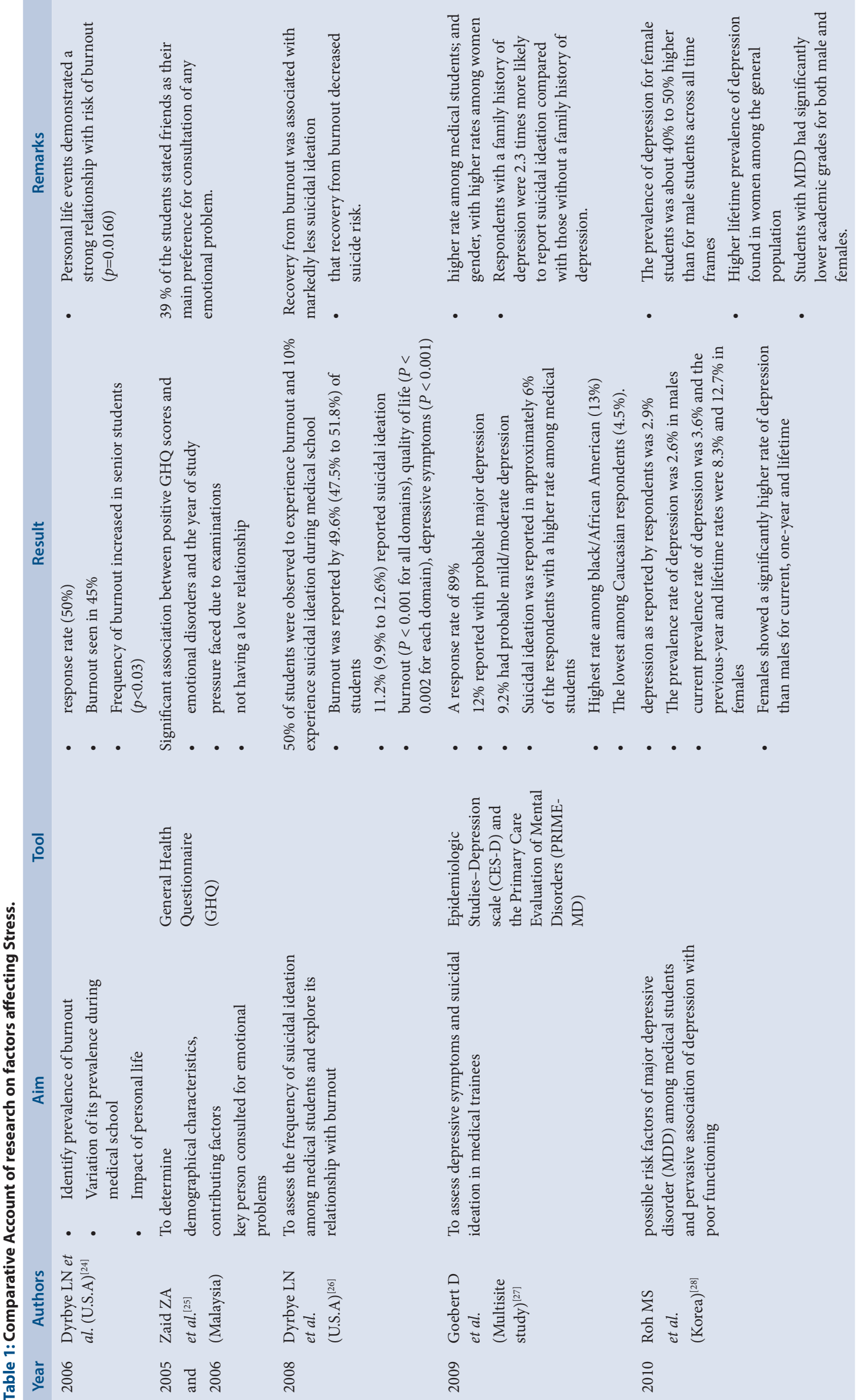


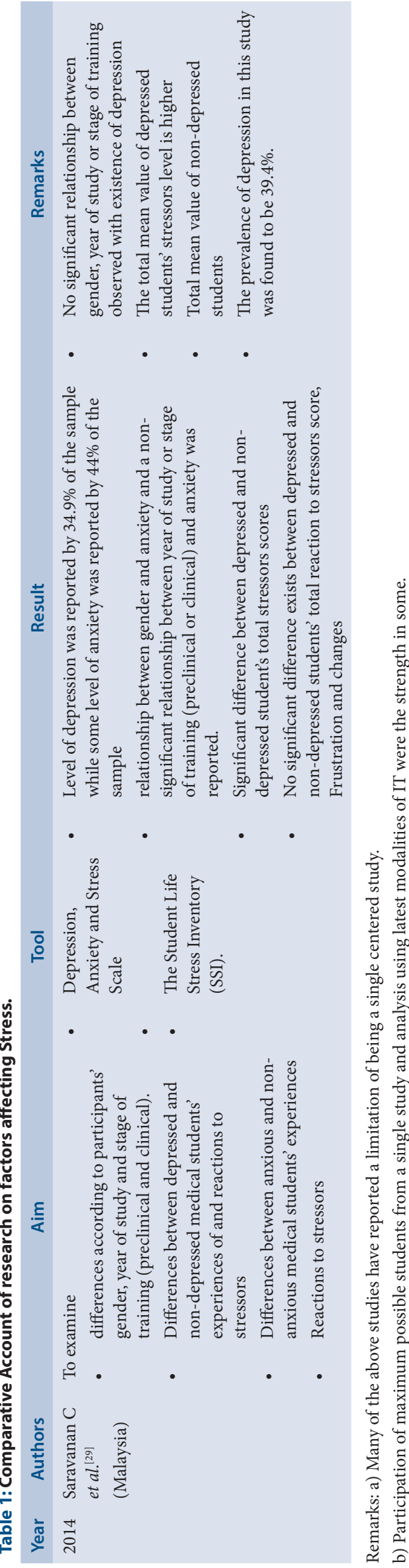

and academic stress level in Medical students during practical examinations in girls was observed to be more as compared to boys. Higher scores of depression, anxiety and stress was found to be associated with female gender, lower semester, younger age and nonsmokers in another research. Semester was also found to be a significant predictor of all the three subscales (depression, anxiety and stress) and gender predicted only the stress sub-scale. The variables, which were used in regression, explained only 7.7 per cent of depression, 7.9 per cent of anxiety and 9.1 per cent of stress. Fifth semester students had highest depression, anxiety and stress scores as compared to others which was predicted to be attributed to greater fear of not attaining their goal of being a doctor or may be due to excessive load of both paraclinical and clinical subjects as compared to only clinical subjects in the latter years. Female respondents had reported higher scores of depression, anxiety and stress compared with their male counterparts which is a common finding with various other studies performed to evaluated stress levels and various stress causing factors. More than $50 \%$ of the medical undergraduate students were reported to be affected by depression, anxiety and stress. ${ }^{[14]}$

In a very recent Iqbal $S$ et al. used a previously validated and standardized instrument, Depression Anxiety Stress Scale (DASS 42) to assess the presence of depression, anxiety and stress among 353 respondent medical undergraduate students. The relation with their socio-demographic and personal characteristics were also acknowledged. The study was conducted in the Institute of Medical Sciences at Bhubaneswar, Odisha, India. $62(17.5 \%)$ students had severe or extremely severe depression. This percentage was 33.4 per cent for anxiety and 13.1 per cent for stress. The mean scores of depression and stress for all students were found to be at mild level and the scores of anxieties at moderate level. ${ }^{[15]}$

\section{Comparative account of stress in students of other faculties}

In India, taking a break of a year or two to prepare for various entrances examinations has become a trend over the years. Students join coaching institutes which teach the how to compete with lacs of other students aiming for the same goal. A combination of low number of seats in colleges and a huge number of students giving the examination has been a major concern as it leaves a large fraction of students who fail to claim a seat in their desired course disheartened. This can leave an impact on the student and not everybody is able to cope with it.

While talking about stress in medical students, other fields are often left out. To have a better comparison of level of stress among students, an anonymous cross-sectional questionnaire-based survey of 100 randomly selected students each from Medical College, Engineering College and 50 Nursing College was done by Behere SP et al. was conducted, out of which, most of the medical students (58\%) were in the age group of less than 20 years, while those of nursing (54.2\%) and Engineering (75\%) were in the age group of 20 to 25 years. It was observed that Seventeen medical students and 11 of engineering students showed denial regarding existing stress, while 35 nursing students showed such trait. Twenty-six medical students, 32 engineering students and 13 nursing students were experiencing normal level of stress and were not blind riding their problems. Five students each from medical and engineering college were having stress of such a degree that requires clinical attention. ${ }^{[16]}$

Setting:A review of the available literature revealed that there had been no published reports directly comparing medical and dental student stress as a focused inquiry using a common survey instrument or theoretical framework. Murphy RJ et al. carried out a comparative study which highlighted differences in the potential stressors affecting each of these groups. The study included a group of 290 medical and dental students to compare alleged stress levels encountered by them. The survey question responses were grouped into five causal categories: 
academic performance, faculty relations, patient and clinic responsibilities, personal life issues and professional identity. A modified version of the Dental Environmental Stress questionnaire compiled by Westerman et al. ${ }^{[17-18]}$ was used as the original template for the survey. The overall findings of the investigation showed that dental students perceived that they experienced greater levels of stress than medical students in three of the five measured categories. Medical students demonstrated greater stress levels than dental students in the category of professional identity. It also came into light that increasing costs of a professional education have added a new and very significant stressor for both medical and dental students with increasing student debt, in conjunction with increasingly uncertain earning potential, students are concerned about their long-term financial security. ${ }^{[19]} 7$ medical schools in the United States Cross-sectional 2007 and longitudinal 2006 to 2007 cohort study.

\section{Setting}

7 medical schools in the United States

\section{ROLE OF PARENTS}

Parents have a big role to play in a child's career choice. Parental interference has also been recognized as a reason for stress in children. With the development of the society, there is no doubt that the way we live has changed completely. However, this change is now receiving complaints, especially from children, who are under high pressure to meet the expectation of their parents. Conflicts in family also affect a student's life. Being raised by a single parent is still to an extent frowned upon and yet, it's effect on a child is contradicting. On one hand it is seen hat kids who are raised by a single parent can cope with staying alone in hostel while on the other hand, it is also believed to be having a negative impact on the child. Focusing on the influence of family background of a student, A questionnaire-based research by Ajay T Shendarkar et al. was conducted which found that child rearing and parenting have a significant influence $(P<0.05)$ on the stress found amongst the medical students. The reason being, one parent is always available at home for taking care of the offspring when the need arises, thereby providing a sound mental foundation for battling the outer world and newer situations. Other factors being independent living for the first time, families where both parents were working, the students were used to stay on their own and were able to cope with the hostel environment more effectively than those who had a parent always to take care of them. ${ }^{[20]}$

\section{Burn out}

Occupational burnout results from long-term, uncountable job stress. Herbert Freudenberg used the term burnout for the first time. It is defined as the exhaustion of physical or emotional strength usually as a result of prolonged stress or frustration. ${ }^{[21]}$ On comparing the result of prevalence of depression and anxiety among students attending a private university in Malaysia to that of different studies, this percentage was found to be higher than a study of medical students attending an American private university $(19 \%)^{[22]}$ but lower than was found in studies of medical students attending private universities in India (49.1\%) and Pakistan (60\%). ${ }^{[23]}$

\section{CONCLUSION}

Medical schools are expected to produce graduates as competent and healthy physicians, but upon taking a glance at several studies existent in the available literature reflect that plentiful students experience depression during medical schools across the globe. In various studies reviewed, the factors common in them is the high prevalence of stress, anxiety and depression in female gender and first year students also, a variable stress level is seen in students raised by single parent. On comparing with general population, medical students show a higher level of stress which suggests that medical education and training may be partly responsible for students' depression. The stress experience was more common due to academics and seen among all year of medical students with high prevalence in first year students which then declined over the later years of medical education. Other factors that are found to act as stressors are exam stress, repeating a year (or more), staying in hostel, being raised by working parents or financial stress.

To resolve this issue, medical schools should provide psychiatric services to assist students in need, consider reforming curricula to reduce stress in medical training and develop programs for mental health and wellness to help students recognize personal distress and promote well-being. There are evidences of students' attempts to commit suicide all over the world which could have been prevented had they been able to share what they are going through with someone or if people were more sensitive towards the fact that students are a vulnerable group of individuals and need all the support that can be provided to them. If provided with proper social and mental discipline at their educational institutions, they would enhance skills to face challenges easily and find better solutions to problems.

\section{ACKNOWLEDGEMENT}

This article would not have been possible without the kind support and help of all the individuals who participated in the survey.

\section{CONFLICT OF INTEREST}

The authors declare no conflict of interest.

\section{SUMMARY}

Education is one of the basic needs and in turn a right of all human beings. Student life has many benefits, but it also imposes inexorable stress. The environment of medical education and practice has long been considered a stressful one. Stress in medical students is not uncommon and is process orientated. In this review, We began with background reading about the topic, tracing the specific resources, we extensively searched the literature and analyzed the shortcomings and strengths of various workers. The relevant reports were compiled and important conclusions from the studies were laid down in proper chronology. Many studies have described the stressors of medical training and the associated negative consequences on the mental and physical health of medical students. The stressors don't cause anxiety or tension by themselves. Instead, stress results from the interaction between stressors and the individual's perception and reaction to those stressors In short, stress includes the emotional disturbances or changes caused by stressors.A comparison has been done in this review as an attempt to understand better the common stress factors among students across the globe. A review of the available literature revealed that there had been no published reports directly comparing medical and dental student stress as a focused inquiry using a common survey instrument or theoretical framework. Parental interference has also been recognized as a reason for stress in children. The stress experience was more common due to academics and seen among all year of medical students with high prevalence in first year students which then declined over the later years of medical education. Other factors that are found to act as stressors are exam stress, repeating year/s , staying in hostel, being raised by working parents or financial stress. It is observed that reforming curricula to reduce stress in medical training, and develop programs for mental health and wellness to help students recognize personal distress and promote well-being. 


\section{REFERENCES}

1. Behere SP, Yadav R, Behere PB. A comparative study of stress among students of medicine, engineering and nursing. Indian Journal of Psychological Medicine. 2011;33(2):145.

2. Peterlini M, Tibério IF, Saadeh A, Pereira JC, Martins MA. Anxiety and depression in the first year of medical residency training. Med Educ. 2002;36(1):66-72.

3. Aktekin M, Karaman T, Senol YY, Erdem S, Erengin H, Akaydin M. Anxiety, depression and stressful life events among medical students: a prospective study in Antalya, Turkey. Medical Education. 2001;35(1):12-7.

4. Abdulghani HM, AlKanhal AA, Mahmoud ES, Ponnamperuma GG, Alfaris EA. Stress and its effects on medical students: a cross-sectional study at a college of medicine in Saudi Arabia. Journal of Health, Population and Nutrition. 2011;29(5):516.

5. Savtchouk I, Liu SJ. Remodeling of synaptic AMPA receptor subtype alters the probability and pattern of action potential firing. Journal of Neuroscience. 2011;31(2):501-11.

6. Viner R. Putting stress in life: Hans Selye and the making of stress theory. Social studies of science. 1999;29(3):391-410.

7. Lazarus RS. Theory-based stress measurement. Psychological Inquiry.1990; 1(1):3-13.

8. Linn BS, Zeppa R. Stress in junior medical students: relationship to personality and performance. Journal of Medical Education. 1984

9. Singh A, Lal A, Singh S. Prevalence of depression among medical students of a private medical college in India. Online Journal of Health and Allied Sciences. 2011; 9(4).

10. Sarkar D, Saha J. Assessment of stress among first year medical students of Chhattisgarh. IOSR J Dental Med Sci. 2015;14(8):37-40.

11. Supe AN. A study of stress in medical students at Seth GS Medical College. Journal of Postgraduate Medicine. 1998;44(1):1.

12. Dahlin $M$, Joneborg N, Runeson B. Stress and depression among medical students: A cross-sectional study. Medical Education. 2005;39(6):594-604.

13. Mannapur B, Dorle AS, Hiremath LD, Ghattargi CH, Ramadurg U, Kulkarni KR A study of psychological stress in undergraduate medical students at SN Medical College, Bagalkot, Karnataka. J Clin Diagn Res. 2010;4:2869-74.

14. Sharma B, Wavare R, Nigam R, Ch R. A study of academic stress and its effect on vital parameters in final year medical students at SAIMS Medical College, Indore, Madhya Pradesh. Biomedical Research. 2011;22(3)

15. Iqbal S, Gupta S, Venkatarao E. Stress, anxiety and depression among medical undergraduate students and their socio-demographic correlates. The Indian Journal of Medical Research. 2015;141(3):354.

16. Behere SP, Yadav R, Behere PB. A comparative study of stress among students of medicine, engineering and nursing. Indian Journal of Psychological Medicine. $2011 ; 33(2): 145$.

17. Westerman GH, Grandy TG, Ocanto RA, Erskine CG. Perceived sources of stress in the dental school environment. Journal of Dental Education. 1993;57(3):225-31.

18. Grandy TG, Westerman $\mathrm{GH}$, Combs $\mathrm{CE}$, Turner $\mathrm{CH}$. Perceptions of stress among third-year dental students. Journal of Dental Education. 1989;53(12):718-21.

19. Murphy RJ, Gray SA, Sterling G, Reeves K, Du Cette J. A comparative study of professional student stress. Journal of dental education. 2009 Mar 1; 73(3):328-37.

20. Shendarkar AT, Patil V. A study of stressors in medical college students (hostelites) in northern Maharashtra. J Indian Acad Forensic Med. 2013;35(3):227-9.

21. Freudenberger $\mathrm{HJ}$. The staff burn-out syndrome in alternative institutions Psychotherapy: Theory, Research and Practice. 1975;12(1):73.

22. Hendryx MS, Haviland MG, Shaw DG. Dimensions of alexithymia and their relationships to anxiety and depression. Journal of Personality Assessment. $1991 ; 56(2): 227-37$

23. Inam SN, Saqib A, Alam E. Prevalence of anxiety and depression among medical students of private university. Journal-Pakistan Medical Association. 2003;53(2):44-6.

24. Dyrbye LN, Thomas MR, Huntington JL, Lawson KL, Novotny PJ, Sloan JA, et al. Personal life events and medical student burnout: a multicenter study. Academic Medicine. 2006;81(4):374-84

25. Zaid ZA, Chan SC, Ho JJ. Emotional disorders among medical students in a Malaysian private medical school. Singapore Medical Journal. 2007;48(10):895.

26. Dyrbye LN, Thomas MR, Massie FS, Power DV, Eacker A, Harper W, et al. Burnout and suicidal ideation among US medical students. Annals of Internal Medicine. 2008;149(5):334-41.

27. Goebert D, Thompson D, Takeshita J, Beach C, Bryson P, Ephgrave K, et al. Depressive symptoms in medical students and residents: a multischool study. Academic Medicine. 2009;84(2):236-41.

28. Roh MS, Jeon HJ, Kim H, Han SK, Hahm BJ. The prevalence and impact of depression among medical students: a nationwide cross-sectional study in South Korea. Academic Medicine. 2010;85(8):1384-90.

29. Saravanan C, Wilks R. Medical students' experience of and reaction to stress: the role of depression and anxiety. The Scientific World Journal. 2014;2014

Cite this article: Kothari R, Sharma S, Bokariya P. Stress, Stressors and Undergraduate Students: A Mini-Review. Int J Clin Exp Physiol. 2018;5(3):114-9. 